\title{
O TEMPO E O ESPAÇO NO TEXTO LITERÁRIO: PERSPECTIVAS PARA O ENSINO DA LEITURA
}

\section{THE TIME AND SPACE IN THE LITERARY TEXT: PROSPECTS FOR THE TEACHING OF READING}

\author{
Albanyra dos Santos Souza ${ }^{1}$ \\ Universidade Federal do Rio Grande do Norte (UFRN)
}

\begin{abstract}
RESUMO
Este estudo, interessado nas reflexões sobre o ensino da leitura literária e nas ideias sobre tempo e espaço, busca refletir sobre o papel do leitor na construção de sentidos do texto, através da análise da constituição espaço-temporal da obra "Barbáro" (MORICONI, 2013). Para tanto, desenvolvemos uma análise interpretativista, ancorada nas discussões sobre o ensino da leitura literária das Orientações Curriculares Nacionais para o Ensino Médio (2006), de Umberto Eco (2003) e de Rildo Cosson (2010), bem como nas teorizações do Círculo de Bakhtin (2014; 2018) e de teórico contemporâneos que tratam sobre cronotopo, Bemong et al (2015); Machado (2010), Morson e Emerson (2008). Os resultados apontam que para formar um leitor crítico e autônomo é preciso levá-lo a refletir não apenas sobre os significados do texto, como também sobre outros sentidos que somente são percebidos quando partimos da sua constituição espaço-temporal.
\end{abstract}

PALAVRAS-CHAVE: Leitura Literária. Espaço-temporalidade. Ensino.

\begin{abstract}
This study, interested in reflecting the teaching of literary reading and in ideas about time and space, aims to reflect the role of the reader in the construction and meanings at text, through the analysis space-time of the book "Barbáro" (MORICONI, 2013). For this, we developed an interpretative analysis of the book, anchored in the discourses on the teaching literary reading of the National Curricular Guidelines for High School (2006), Humberto Eco (2003) and Rildo Cosson (2010), besides the theories of Bakhtin's Circle $(2014,2018)$ and contemporary scholars talking about chronotope, Bemong et al. (2015); Machado (2010), Morson and Emerson (2008). The results say that to form a critical and autonomous reader it is necessary to lead the student to reflect not only the meanings at texts, but also on other senses that only we perceive when begin the analysis of its space-temporality constitution.
\end{abstract}

KEY WORDS: Literary Reading. Space-temporality. Teaching.

\section{INTRODUÇÃO}

Neste estudo, partimos da concepção de que a leitura é fundamental para o desenvolvimento e a participação dos sujeitos em sociedade. Adotamos a concepção de leitura interacional dialógica da língua, a qual considera os sujeitos como atores/construtores sociais que dialogicamente constroem e são construídos no texto, considerando o próprio lugar da interação e da constituição dos interlocutores. Nessa concepção de leitura, o sentido do texto é construído na interação texto/sujeitos, e a leitura se organiza como uma atividade de interação altamente complexa de produção de sentidos. Podemos considerar, então, que há no texto espaço para uma

\footnotetext{
${ }^{1}$ Doutoranda em Estudos da Linguagem pela Universidade Federal do Rio Grande do Norte. Trabalho produzido na pós-graduação lato sensu em Literatura e Ensino, pelo Instituto Federal de Educação, Ciência e Tecnologia do Rio Grande do Norte. E-mail: albanyra.souza@hotmail.com.
} 
gama de implícitos, dos mais variados tipos, somente detectáveis quando se tem, como pano de fundo, o contexto sociocognitivo dos participantes da interação.

Os efeitos de sentido do texto, através da sua constituição espaço-temporal, fazem-se sentir ao longo da narrativa, constituindo-se assim, uma ferramenta eficaz para compreensão e interpretação do texto em análise.

Para tanto, nosso objetivo é refletir o papel do leitor na construção de sentidos do texto, através da análise da constituição espaço-temporal da obra "Barbáro" (MORICONI, 2013). Apoiamo-nos nas discussões das Orientações Curriculares Nacionais para o Ensino Médio sobre o ensino da leitura literária (BRASIL, 2006), nas teorizações de Umberto Eco (2008) e Rildo Cosson (2010) que tratam da temática, como também nas concepções do Círculo de Bakhtin sobre cronotopo (2014; 2018) e de estudiosos contemporâneos Morson e Emerson (2008), Bemong et al (2015) e Irene Machado (2010).

O artigo está organizado, então, da seguinte forma: breves considerações iniciais; seguidas de duas seções teóricas que tratam da leitura do texto literário e sobre o cronotopo bakhtiniano; os dados metodológicos; a análise dos dados, incluindo duas seções sobre a narrativa da obra e a análise do tempo e do espaço que constitui a narrativa; e por último, as considerações finais.

\section{A leitura do texto literário}

Quando pensamos em abordar a temática da leitura do texto literário, juntamente sentimos a necessidade de refletir acerca do papel do leitor e ainda dos efeitos de sentido que o texto literário possibilita. Nesse sentido, ratificamos o questionamento já posto nas Orientações Curriculares Nacionais para o Ensino Médio (2006, p. 66): "A leitura do texto literário possibilita a irrefreável disseminação de sentidos, tantos quantos forem os leitores que o fertilizem com seu olhar?". Para responder o questionamento, o documento traz vozes de Umberto Eco (2003), quando afirma que as obras literárias nos convidam à liberdade de interpretação, pois propõe um discurso com muitos planos de leitura e nos colocam diante das ambiguidades e da linguagem da vida.

Nesse entendimento, os diferentes leitores assumem posicionamentos interpretativos que podem variar conforme uma série de fatores que interferem diretamente no processo de compreensão do texto, como por exemplo a bagagem cultural que o leitor traz para a sala de aula, suas vivências, hábitos e costumes. Além disso, para captar os efeitos de sentidos do texto literário é necessário que o leitor esteja atento ao que Rildo Cosson (2010) chama de espaço do contexto e espaço do intertexto. Para o autor, o espaço do contexto se relaciona à realidade de mundo a ser depreendida no ato da leitura, ou seja, diz respeito às referências ou aos dados consistentes relacionados a uma ou outra área do conhecimento, é a contextualização. Já o espaço do intertexto está ligado a vinculação entre textos e a adoção da premissa segundo a qual um texto é resultante do diálogo com outros textos. Essa intertextualidade pode ser externa - relação explícita entre dois ou mais textos - ou ainda interna - relação implícita entre dois ou mais textos.

Esses dados são relevantes quando relacionamos a leitura literária não apenas com a necessidade de informação do sujeito leitor, mas com a necessidade de formação do leitor na escola. Por isso, muitos questionamentos persistem, como por exemplo que leitor formar, como abordar o ensino da literatura em sala de aula? Conforme as orientações dos documentos oficiais, é inquestionável formar o gosto literário em sala de aula, conhecer a tradição literária local e oferecer instrumentos para um conhecimento maior nas obras literárias, porém o questionável são os métodos que têm sido utilizados para esses fins ao longo dos anos.

O documento ainda enfatiza que:

Veja-se que a tarefa é bastante difícil, uma vez que a ficção juvenil, que tem sido quase hegemônica no ensino fundamental, ou os best-sellers não são suficientes para lançar o jovem no âmbito mais complexo da leitura literária, pois nesses casos a experiência ainda se mantém restrita a obras consagradas pela mídia e também 
àquelas que oferecem um padrão linguístico próximo da linguagem cotidiana. $\mathrm{O}$ desafio será levar o jovem à leitura de obras diferentes desse padrão - sejam obras da tradição literária, sejam obras recentes, que tenham sido legitimadas como obras de reconhecido valor estético - capazes de propiciar uma fruição mais apurada, mediante a qual terá acesso a uma outra forma de conhecimento de si e do mundo. (BRASIL, 2006, p. 69-70)

Nesse entendimento, o desafio está em aproximar o aluno-leitor de textos que proporcionem um valor estético, conhecimento cultural e marcas de um povo que possui história a ser contada e transmitidas para as gerações futuras.

Busca-se a formação de um leitor crítico, aquele que não se interessa apenas com "o quê" o texto conta, mas em "como" o texto é contado, e todas as questões críticas que circundam a produção textual, seu contexto, seu intertexto e o próprio texto.

\section{Situando o cronotopo}

As teorizações acerca do conceito de cronotopo foram escritas e publicadas por Bakhtin em Questões de Literatura e Estética (2014) - "Formas de tempo e de cronotopo no romance (ensaios da poética histórica), em ensaios sobre tempo e espaço nos escritos de Rebelais, e ainda na obra Estética da Criação Verbal (2011) - "O tempo e o espaço nas obras de Goethe”. Nos textos, o autor apresenta análises referentes a aspectos espaço-temporal do gênero romance. Bakhtin afirma que "Qualquer intervenção na esfera dos significados só se realiza através da porta dos cronotopos" (BAKHTIN, 2014, p. 362), ou seja, o cronotopo é a porta de entrada para a compreensão dos significados, seja no estudo do romance, ou de qualquer outro gênero discursivo.

Acerca do entendimento do conceito de cronotopo, Bakhtin (2014) explica que esse é um termo empregado nas ciências matemáticas, introduzido e fundamentado na teoria da relatividade de Einstein e transportado para a crítica literária. Na palavras do autor,

À interligação fundamental das relações temporais e espaciais, artisticamente assimiladas em literatura chamaremos cronotopo (que significa "tempo-espaço"). Esse termo é empregado nas ciências matemáticas e foi introduzido e fundamentado com base na teoria da relatividade (Einstein). Não é importante para nós esse sentido específico que ele tem na teoria da relatividade, assim como o transportaremos daqui para a crítica literária quase como uma metáfora (quase mas não totalmente); nele é importante a expressão de insolubilidade de espaço e de tempo (tempo como quarta dimensão do espaço). Entendemos o cronotopo como uma categoria conteudístico-formal da literatura. (BAKHTIN, 2014, p. 211, grifos do autor)

Para entender a indissolubilidade de tempo e espaço, Bakhtin ressignifica o conceito de cronotopo no campo literário, e busca analisar, por exemplo, os diversos cronotopos que se instauram no romance - o cronotopo do encontro, o cronotopo da estrada, "No romance os encontros ocorrem frequentemente na 'estrada'. Ela é o lugar preferido dos encontros casuais." (BAKHTIN, 2014, p. 349, grifos do autor). É na estrada que os caminhos espaço-temporais das mais diferentes pessoas se cruzam, pessoas separadas pela hierarquia social e pelo espaço, porém com destinos cruzados pela metaforização do caminho-estrada.

Destaca-se ainda o cronotopo da soleira, com características que se aproximam do tema do encontro, contudo substancialmente mais completo, "[...] é o cronopoto da crise e da mudança de vida" (BAKHTIN, 2014, p. 354). Bakhtin trata também dos cronotopos em Dostoievsky,

Em Dostoievsky, por exemplo, o limiar e os cronotopos da estrada, da antessala, do corredor, que lhes são contíguos, e também os cronotopos da rua e da praça, que lhes seguem, são os principais lugares da ação nas suas obras, são os lugares 
onde se realizam os acontecimentos das crises, das quedas, das ressurreições, dos renascimentos, das clarividências, das decisões que determinam toda uma vida. (BAKHTIN, 2014, p. 354)

Em seus estudos, Bakhtin buscou descrever os “[...] 'cronotopos maiores' que definem o gênero e constituem o principal campo para eventos em mundos particulares" (MORSON; EMERSON, 2008, p. 442, grifos dos autores). Todavia, nos limites de uma obra observamos uma grande quantidade de cronotopos, sendo um deles englobador e dominante, conforme também interpreta Bemong et al (2015, p. 22) “[...] a interpretação entre as unidades cronotópicas concretas de uma narrativa deixa o leitor com uma impressão global, a que chamamos de cronotopo maior on dominante" (grifos do autor). Nos estudos de Bakhtin, foram esses cronotopos maiores o objeto de análise.

Bakhtin (2014) afirma que os cronotopos são característicos de vários significados, dentre eles o significado temático e figurativo. Sobre o significado temático, os cronotopos são centros organizadores dos principais acontecimentos temáticos do romance, "Pode-se dizer francamente que a eles pertence o significado principal gerador do enredo." (BAKHTIN, 2014, p. 355). O significado figurativo dos cronotopos relaciona-se a concretização dos acontecimentos do enredo, uma vez que "O próprio cronotopo fornece um terreno substancial à imagem-demonstração dos acontecimentos. Isso graças justamente a condensação e concretização espacial dos índices do tempo [...] em regiões definidas do espaço." (BAKHTIN, 2014, p. 355).

Nas colocações de Bemong e Borghart (2015, p. 22), Bakhtin situa o significado dos cronotopos em pelo menos quatro itens diferentes: "Eles têm significado na geração da narrativa do enredo, da trama; têm significado representacional; fornecem a base para discutir os tipos de gêneros; e têm significado semântico", ou seja, na observação dos autores, são vários os significados que surgem dos cronotopos, desde a geração da narrativa, sua constituição representacional e genérica, até o seu caráter de significado semântico.

Machado (2010, p. 212), ao refletir sobre a temática, afirma que o "Cronotopo se firmou como uma categoria que define não apenas o continuum espaço-tempo, mas a semiose de diferentes sistemas se signos [...]" (grifos da autora). O tempo e o espaço são construídos na composição da obra literária como texto de cultura, uma vez que os signos da cultura fazem parte da sua composição. Nas palavras a autora,

O cronotopo foi concebido como uma forma arquitetônica da narrativa que configura modos de vida em contextos particulares de temporalidades. O tempo, para Bakhtin, torna-se pluralidade de visões de mundo: tanto na experiência quanto na criação, manifesta-se como um conjunto de simultaneidades de que não são instantes, mas acontecimentos no complexo de seus desdobramentos. A pluralidade de que fala Bakhtin só pode ser apreendida no grande tempo das culturas e das civilizações, quer dizer, no espaço. (MACHADO, 2010, p. 214)

Nessa direção, a narrativa e os gêneros do discurso são instâncias estéticas de representação do tempo-espaço. Na orientação dialógica de investigação bakhtiniana, tempo e espaço configuram modos de vida em contextos particulares, simultaneidade de experiências, acontecimentos complexos que emergem de ações particulares. Os gêneros, bem como as narrativas tornam-se campo fértil de investigação, uma vez que neles se constroem os discursos sobre o mundo.

\section{Dados metodológicos}

Para a análise da obra "Bárbaro" (MORICONI, 2013), será adotada a abordagem de investigação qualitativa-interpretativista (BOGDAN; BLIKEN, 1994), que tem como característica, neste estudo, ser descritiva, se constituir enquanto caminhos interpretativos no decorrer da investigação, preocupar-se com o processo, os significados da narrativa para o leitor e 
a contribuição do tempo-espaço na constituição dos significados da obra, cujos sentidos possam ser significativos para o ensino da Literatura.

A obra é uma produção do escritor e ilustrador Renato Moriconi, publicada em 2013 pela Companhia das Letrinhas e vencedora do prêmio "30 melhores livros infantis do ano, Crescer 2014" e o prêmio "Jabuti em Melhor Ilustração de Livro Infantil e Juvenil". O escritor paulista estudou artes plásticas e design gráfico; tem mais de 40 livros publicados no Brasil e também em outros lugares do mundo, como França, México e Coreia do Sul. Ao longo de sua carreira, recebeu alguns prémios como o de Melhor Livro-Imagem, em 2011, e de Melhor Livro para Criança, em 2012, pela Fundação Nacional do Livro Infantil e Juvenil. Ainda foi finalista do prêmio Jabuti 2011 nas categorias Melhor Ilustração Infantil e Melhor Livro Infantil.

Vejamos quais os caminhos interpretativos percorridos pelo leitor ao longo da obra.

\section{Entendendo a narrativa da obra}

A obra infanto-juvenil, é uma composição literária escrita através de desenhos ilustrativos que dão conta de todo o enredo. Eles desempenham uma variedade de funções relacionadas à orientação de leitura, estímulo de interesse, curiosidade, ilustração de ideias, argumentos e, principalmente, relação de descrição de fatos sonhados e vividos.

O título da obra dá pistas ao leitor sobre o seu conteúdo, leva-o a relacionar os significado da palavra com a ilustração de uma cavaleiro montado em um cavalo, prontos para a batalha. Os personagens estão dispostos em posição central na capa do livro, com uma linha vertical que os cruza, conforme pode ser visto na figura 1.

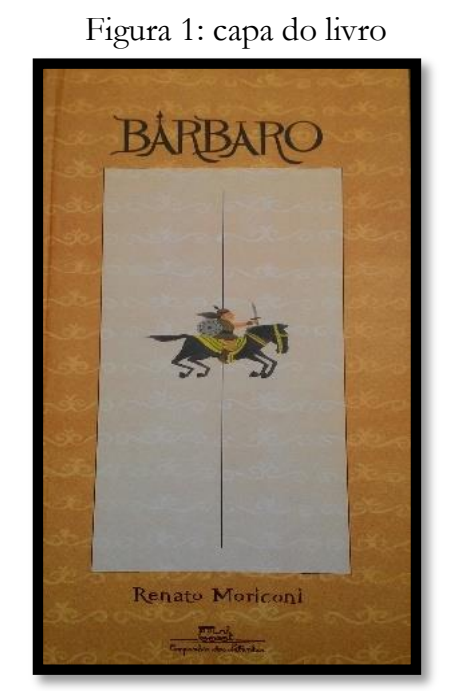

Fonte: MORICONI, Renato. Bárbaro. São Paulo: Companhia das Letrinhas, 2013.

Cada passagem da narrativa é representada em páginas duplas, com detalhe da não paginação. São fatos narrados sem interrupção, cujo tempo já manifesto se faz entender como transitório e mítico. Ou seja, embora o tempo seja marcado rapidamente pela mudança dos acontecimentos, o cavaleiro vive cada momento intensamente. $\mathrm{Na}$ figura 2, a seguir, observamos um guerreiro com sua espada e escudo de proteção nas mãos em direção ao seu cavalo. Nessa imagem, destacamos a forma serena como se encontra o guerreiro, em terra firme, olhos e boca fechados, com aspecto tranquilo, cabelos ao vento, pronto para a batalha. Os detalhes podem ser observados na ilustração a seguir: 


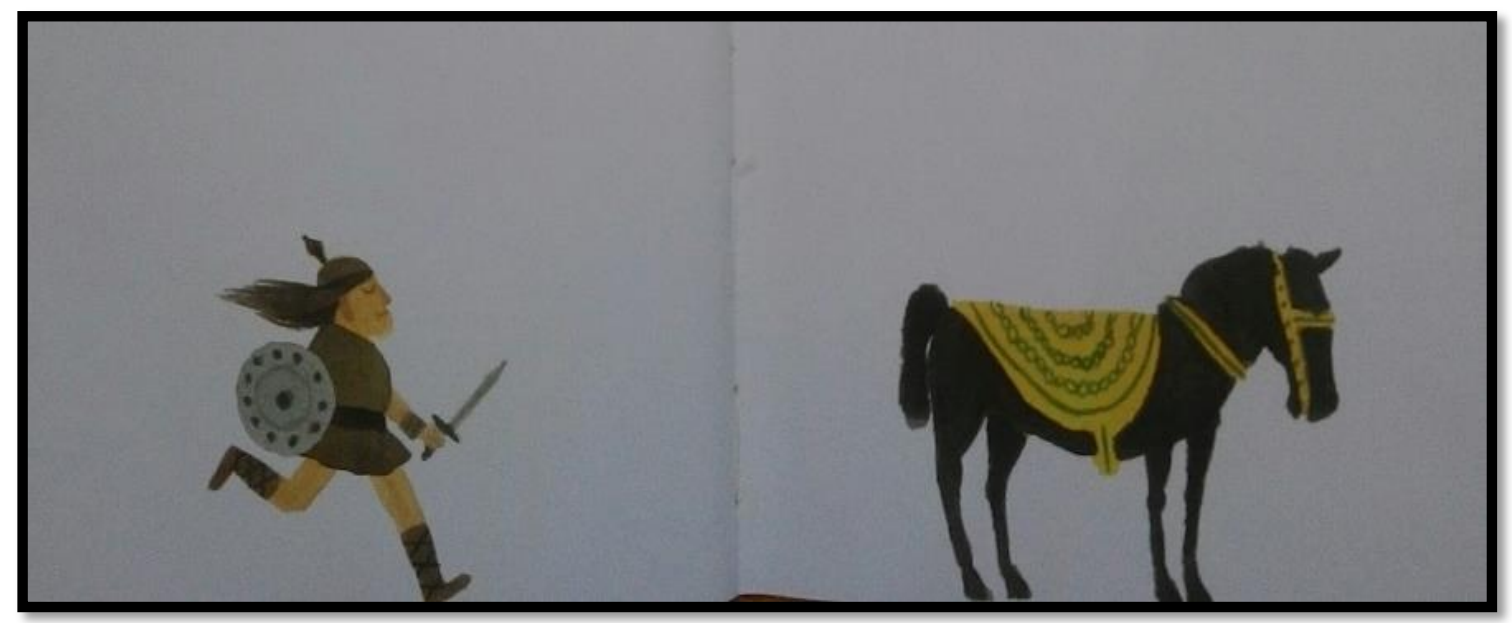

Fonte: MORICONI, Renato. Bárbaro. São Paulo: Companhia das Letrinhas, 2013.

Destacamos ainda na figura 2, outros elementos representativos de contextos bélicos, como por exemplo o elmo ou também conhecido como capacete militar, caracteristicamente utilizado para defender a cabeça dos soldados nos espaços bélicos; o escudo de proteção ou pavês e espada, instrumentos usados para defesa e ataque; botas trançadas meia perna para proteção física; e cavalo com manto amarelo que se assemelha a uma armadura, cujo animal encontra-se em posição de partida.

$\mathrm{Na}$ sequência das imagens, observamos obstáculos vencidos, animais selvagens que ameaçam atacar, um guerreiro pronto para a batalha, permanência de suas características físicas, e a sensação de vitória na luta contra os possíveis inimigos. A sequência do enredo pode ser observada nas figuras a seguir:

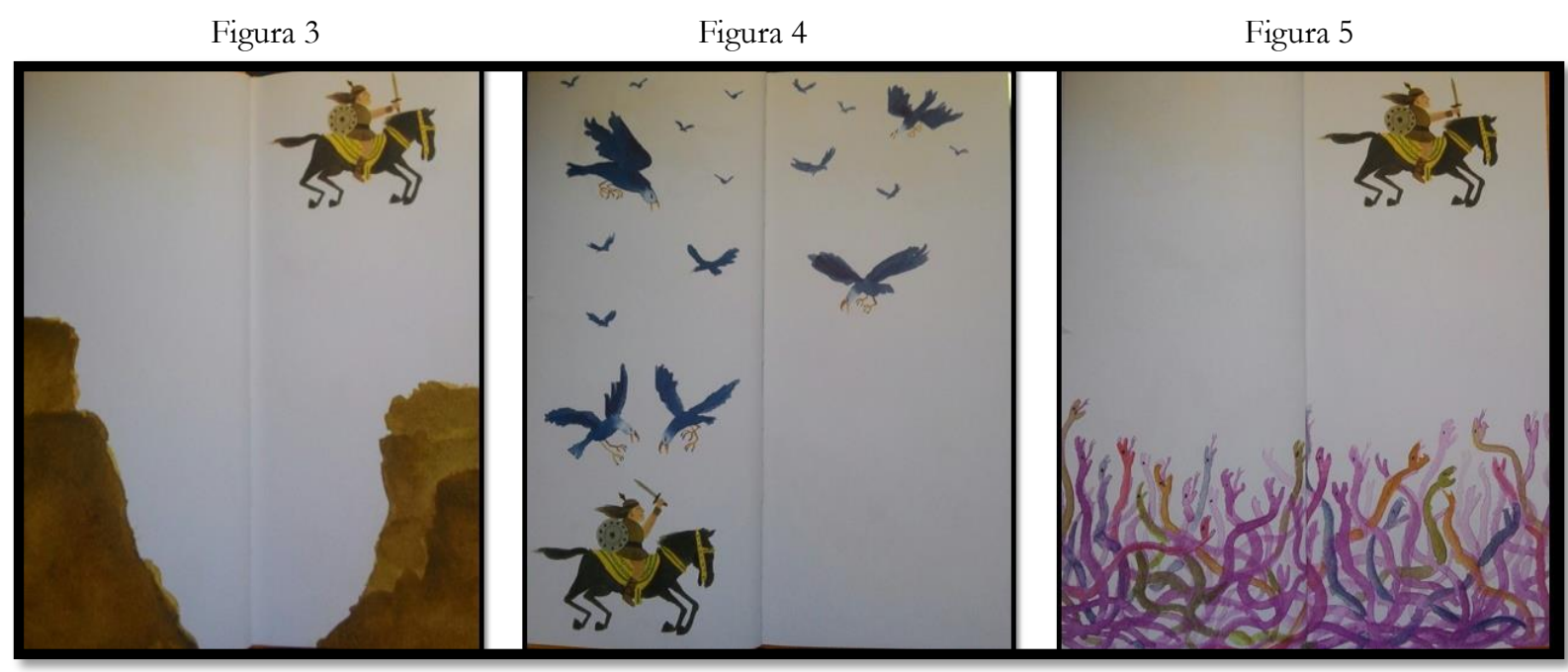

Fonte: MORICONI, Renato. Bárbaro. São Paulo: Companhia das Letrinhas, 2013.

\footnotetext{
2 Imagem aproximada para captar os detalhes.
} 
$\mathrm{Na}$ figura 3, embora montado em um cavalo não alado, o guerreiro voa entre as montanhas, vencendo o primeiro obstáculo. A ilustração mostra movimento constante, percebido, principalmente pela disposição do cabelo. Na figura 4, o soldado luta contra aves de rapina gigantes que o sobrevoam e o atacam. Mas, forte e resistente, ele parece não se intimidar com os animais, seu semblante continua sereno. Na figura 5, o guerreiro segue seu trajeto vencendo serpentes. Elas são em grande quantidade, coloridas, longas, com bocas grandes e abertas, porém não conseguem vencer o cavaleiro.

$\mathrm{Na}$ sequência, a figura 6 narra o guerreiro sendo atacado por flechas que surgem do alto sendo lançadas na sua direção. $\mathrm{Na}$ figura 7 , enfrenta ciclopes ${ }^{3}$, seres gigantes com características peculiares. Já na figura 8 , mesmo sendo atacado por um ser híbrido, cujas características denotam um cão com aspectos de leão e calda de escorpião, a expressão facial de serenidade do personagem não se altera, seguindo feliz sua batalha em busca do próximo obstáculo. As imagens podem ser vistas a seguir:

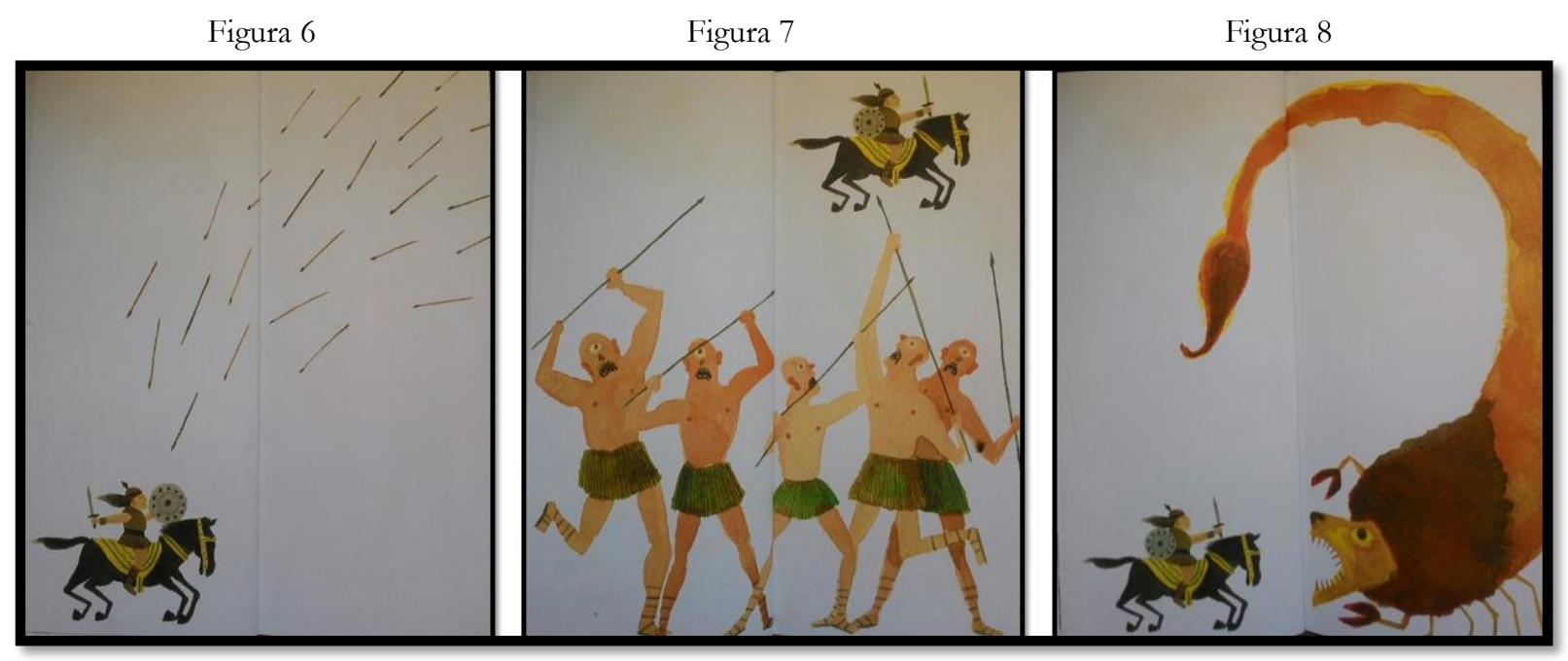

Fonte: MORICONI, Renato. Bárbaro. São Paulo: Companhia das Letrinhas, 2013.

A próxima batalha é vencer seres da natureza conhecidos como plantas carnívoras ${ }^{4}$. Nesse duelo, conforme figura 9 apresentada a seguir, o guerreiro, embora alvo de ataque, aparece como vencedor. $\mathrm{Na}$ figura 10, gárgulas ${ }^{5}$ com garfos gigantes o sobrevoam. Esses seres grotescos são representativos do estilo gótico medieval e inspiram, de alguma forma, pesadelos humanos. $\mathrm{Na}$ narrativa, esse ser híbrido, também com características de morcego, é assustador e violento. Semelhantemente, na figura 11, um dragão gigante com traços de jacaré também tenta atacá-lo. Esse animal, embora se apresente com características de uma dragão, não cospe fogo pela boca como manda o imaginário, porém demonstra valentia e ferocidade. As imagens podem ser vistas a seguir:

\footnotetext{
${ }^{3}$ Os ciclopes, gingantes imortais na mitologia Grega "Eram seres monstruosos, gigantescos e com um olho só no meio da testa. Viviam sem lei e eram pastores. Nem aravam a terra nem tinham cidades. Suas casas eram cavernas situadas no alto das montanhas" (VASCONCELOS, 1998, p. 69).

4 As plantas carnívoras, para os estudos biológicos, são plantas de beleza exótica. Alimentam-se principalmente de insetos, além de diversos organismos aquáticos microscópicos, moluscos (lesmas e caramujos), artrópodes (insetos, aranhas e centopeias), e excepcionalmente pequenos vertebrados, como sapos, pássaros e roedores (MATOS, 2012).

5 “As gárgulas representam um dos casos mais interessante do discurso ortodoxo. $\mathrm{Na}$ sua variedade, predominam os monstros marinhos e infernais, bem como figurações humanas [...] de grande sentido burlesco [...]. Na maior parte, são testemunhos da iconografia tradicional do Ocidente para a representação dos vícios e pecados mortais[...]" (GOMES, 1997, p 70, 158).
} 


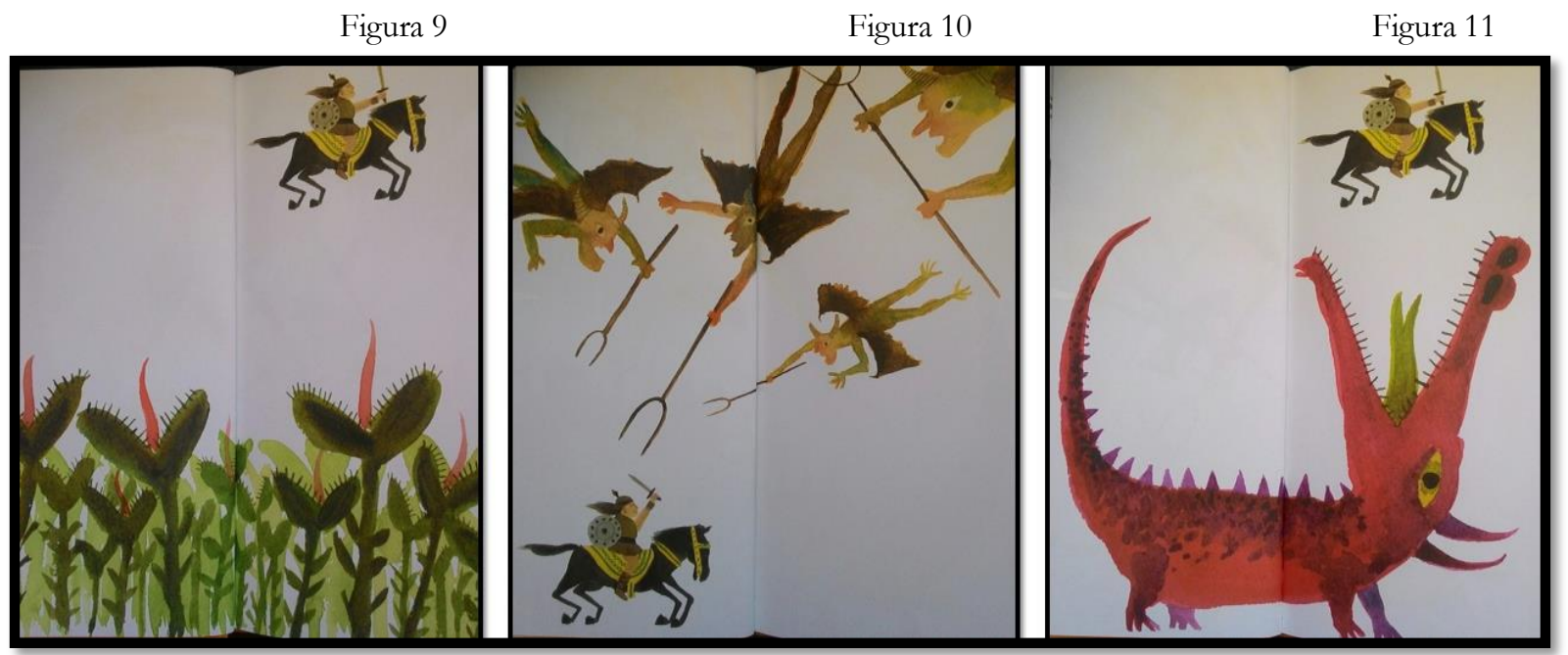

Fonte: MORICONI, Renato. Bárbaro. São Paulo: Companhia das Letrinhas, 2013.

Já na figura 12 que segue, temos o inimigo das nuvens cinzentas tentando arruinar o trajeto do guerreiro, uma espécie de semideus que está para além da terra e lança raios em direção ao guerreiro. Essa divindade da tempestade perece se dirigir em forma de ataque, mas o semblante sereno e vitorioso do guerreiro nos faz perceber que nem mesmo os raios são capazes de alcançálo. Ele avança para a próxima batalha, figura 13, lutar contra um animal meio jacaré meio serpente que paira sobre as águas, gigante e feroz.

Seus inimigos são vários e o caminho é tortuoso. Como demonstra a figura 14, ele precisa enfrentar mais um animal ciclópico e voador, um tipo de ave de rapina negra que cospe fogo, por isso também semelhante a um dragão. As chamas lançadas passam próximo ao guerreiro, mas em seu cavalo galopante ele parece ser indestrutível e todos esses inimigos são facilmente vencidos ao longo da sua cavalgada conflituosa e cheia de desafios.

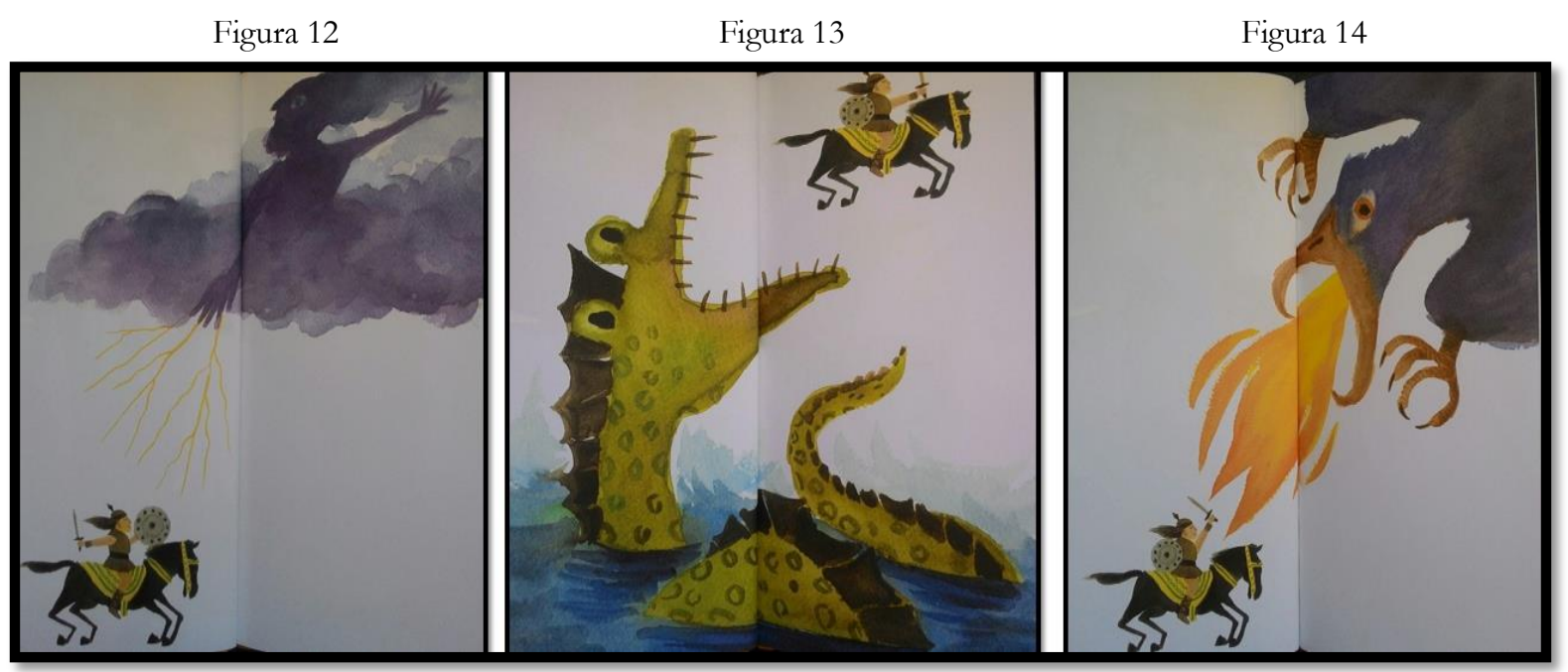

Fonte: MORICONI, Renato. Bárbaro. São Paulo: Companhia das Letrinhas, 2013.

Mas a batalha não tem fim, há um incêndio ainda para ser vencido, muito fogo que se alastrou e tomou conta de uma grande parte da cena, figura 15 na sequência, obstáculo também vencido. Ele segue seu caminho afora, em busca do próximo monstro, animal feroz ou qualquer inimigo que venha a cruzar o seu caminho. Sua expressão facial continua serena, confiante, e seu 
cavalo não para de seguir, sempre em frente, conforme figura 16. Porém, quando chegamos na figura $17 \ldots$ Vejamos as imagens:

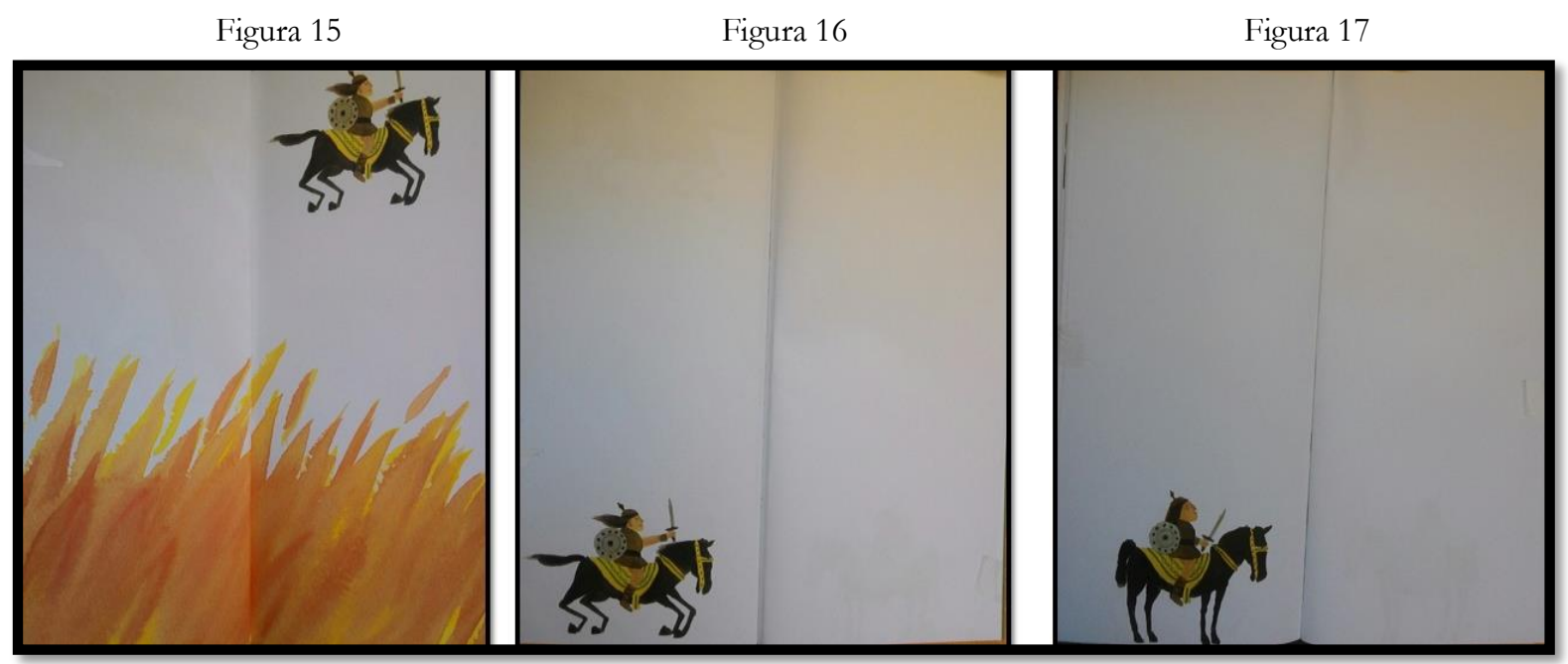

Fonte: MORICONI, Renato. Bárbaro. São Paulo: Companhia das Letrinhas, 2013.

O que aconteceu? O que provocou a mudança de expressão facial do guerreiro? Aconteceu uma quebra de expectativa, tanto do personagem, quanto do leitor. $\mathrm{Na}$ figura 18 (figura 17 aproximada) percebemos traços faciais diferentes de todas as imagens anteriores. Conforme as cenas vão sendo apresentadas na sequência, a tristeza vai se tornando aparente e se intensificando cada vez mais. Algo inesperado está acontecendo com valente, conforme as imagens:
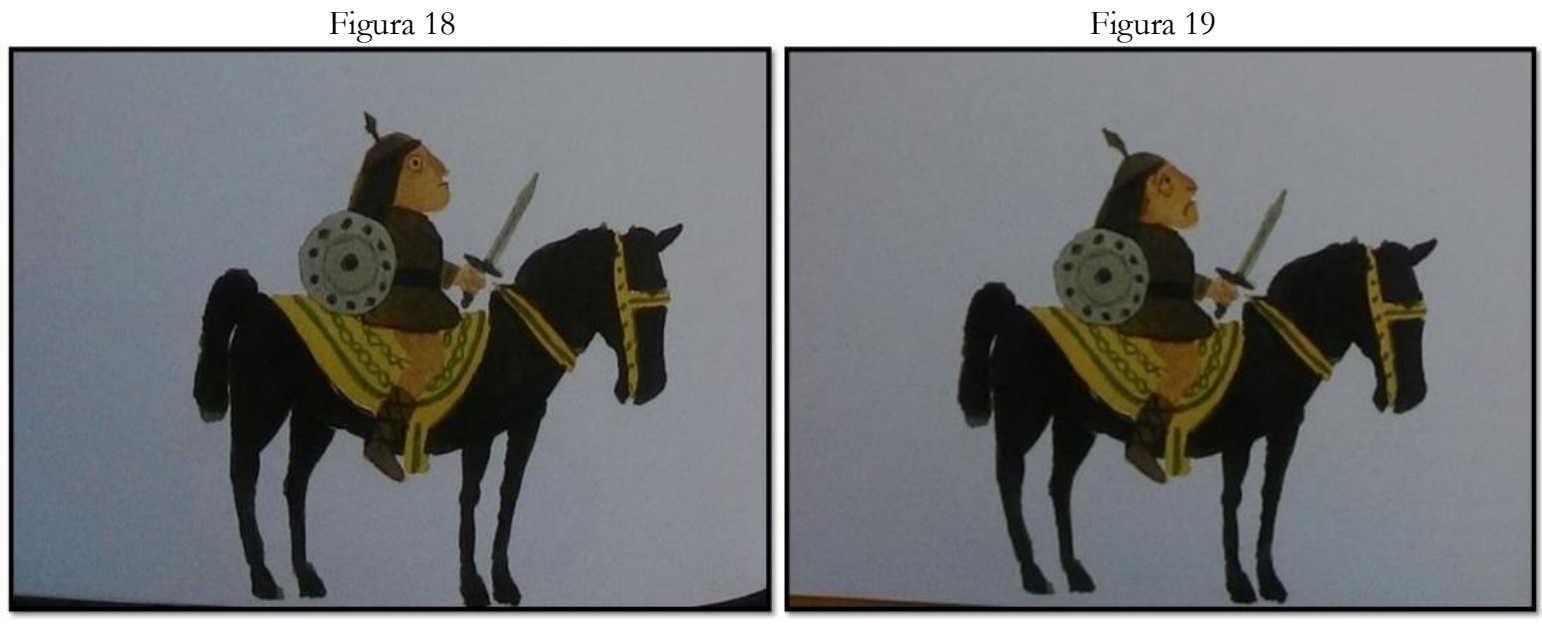

Fonte: MORICONI, Renato. Bárbaro. São Paulo: Companhia das Letrinhas, 2013.

A figura 20 a seguir, surpreendentemente, apresenta uma quebra de expectativa, pois o guerreiro forte e valente não passa agora de um garoto chorão montado em seu cavalo. Diante dele está um homem grande de braços estendidos, sério, olhos fechados, com semblante confiante. $\mathrm{O}$ desfecho da narrativa está posto na figura 21, quando fica claro que aquele cavaleiro valente e forte agora é um menino chorão saindo de em um carrossel. Os braços estendidos do homem na figura 20 retrata um responsável pela criança (quem sabe seu pai) que veio buscá-lo, também representado na figura 21. Vejamos as imagens: 


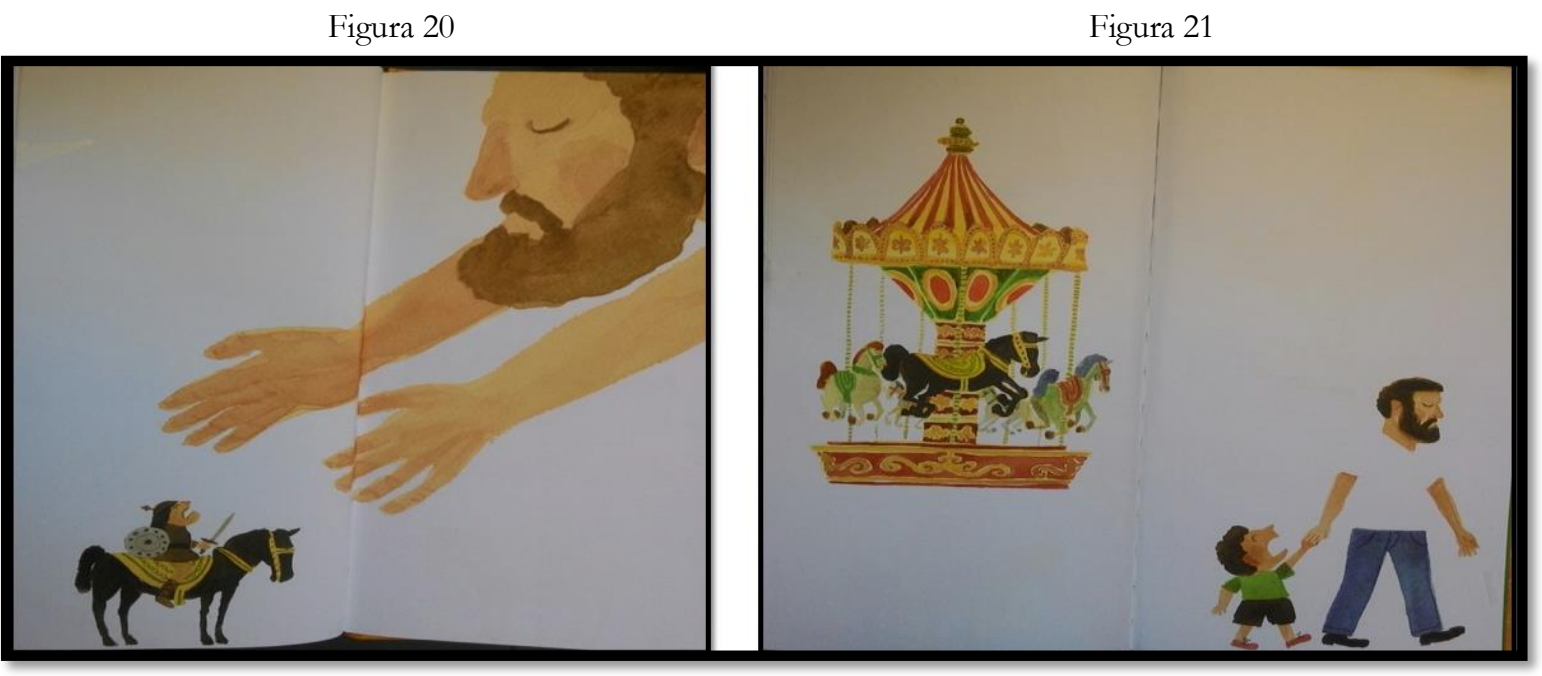

Fonte: MORICONI, Renato. Bárbaro. São Paulo: Companhia das Letrinhas, 2013.

Ao longo da narrativa, algumas pistas são dadas ao leitor para que se compreenda a construção do enredo e a sua relação com o carrossel que figurava no final da Idade Média. Nesse período, havia uma dinâmica entre nobres cavaleiros em suas montarias em círculos, denominada carrossel. Na obra, o carrossel representa as fases da cavalgada. As etapas imaginadas e vividas pelo guerreiro remetem a paisagens e representações medievais da antiguidade, como por exemplo, os cavaleiros em guerra, os ciclopes, as gárgulas, as serpentes gigantes, os dragões, enfim, figuras características desse período histórico ${ }^{6}$.

$\mathrm{Na}$ figura 1, a capa do livro, o autor ilustra o seu personagem em posição central, suspenso em uma linha vertical, que relembra a parte central do carrossel. Na sequência, na maioria das figuras, o guerreiro é mostrado com a mesma expressão facial, sereno, confiante, olhos fechados, seu cavalo em posições fixas, ou seja, embora haja o movimento das batalhas vividas, as patas do cavalo não se movimentam, estão sempre na mesma posição (conforme figuras 3 a 16). Além disso, o ritmo de passeio do carrossel é mantido ao longo da narrativa, ora o cavalo sobe, ora o cavalo desce, típico das aventuras do brinquedo.

Um último aspecto também relevante é perceber algumas características físicas do guerreiro. Durante quase todo o trajeto (figura 3 a 16) ele está com os cabelos ao vento, olhos fechados, cabeça erguida e braços levantados, sinalizando a transitoriedade e a idealização da aventura. A partir da figura 17, novas características são percebidas indicando as várias temporalidades que são vividas pelo guerreiro e os diferentes espaços. Vejamos um pouco mais sobre o tempo e o espaço na narrativa.

\section{O tempo e o espaço}

Para analisar o tempo e o espaço da obra, partimos das ideias de que os indícios do espaço e do tempo se fundem no cronotopo artístico-literário, o tempo ganha corporeidade e torna-se artisticamente visível, enquanto o espaço se intensifica e se incorpora ao movimento do tempo, do enredo e da história. Nesse contexto, “[...] os sinais do tempos se revelam no espaço e o espaço é apreendido e medido pelo tempo. (BAKHTIN, 2018, p. 12).

Mas de qual tempo e espaço estamos falando? $\mathrm{Na}$ obra, nos chama a atenção um tempo e um espaço que vai se construindo ao longo da narrativa. Inicialmente, identificamos o tempo

\footnotetext{
${ }_{6}^{6}$ Para entender um pouco mais sobre a simbologia do carrossel na Idade Média, ver a obra: BURKE, Peter. A fabricação do rei: a construção da imagem pública de Luís XIV. Rio de Janeiro: Jorge Zahar, 1994.
} 
aventuresco que se materializa na transitoriedade das aventuras vividas pelo guerreiro e se interioriza em espaços típicos de construções imagéticas próprias das aventuras. Há a presença de um tempo variadamente abstrato e subjetivado na construção do herói e dos objetos completares à narrativa. Esse tempo da aventura e das construções imagéticas chamamos de sentido extratemporal, "[...] o que dura muito pouco no tempo real [...]" (BAKHTIN, 2018, p. 105). Conforme apresentadas na seção anterior, o livro narra as aventuras de um guerreiro sonhador que vive em dois tempos simultaneamente, considerados a heterotemporalidade: o tempo imaginado, o extratemporal, e o tempo vivido real, a real-temporalidade.

Quando falamos da heterotemporalidade, estamos tratando de dois tempos que se unem e constituem um todo, o tempo da aventura e o tempo da realidade. Eles ocorrem simultaneamente, identificado em quase toda a narrativa, nas figuras de 1 a 20 (conforme apresentadas na seção anterior).

O tempo aventuresco, extratemporal, também está relacionado a ideia de identidade, capaz de significar apenas nesse tempo e espaço específicos: o tempo da aventura e o espaço abstrato. Nessa fusão de tempo e espaço surgem o herói, os seres monstruosos, os animais selvagens, as plantas animalizadas. São identidades provisórias que integram a realidade vivida e os momentos sonhados. Esse tempo é marcado pela simultaneidade das batalhas num espaço abstrato, repleto de raridades casuais e curiosidades. Nesse tempo, o acaso revela um atrativo mágico e misterioso, cujo herói não experimenta insucesso nas lutas contra os inimigos, ao contrário ele vive aventuras maravilhosas e encantadoras para si mesmo. Esse tempo, constitui precisamente a narrativa representada nas figuras de 1 a 15 . Nas imagens, o jogo subjetivo com o tempo e o espaço se instaura. Essa subjetividade é marcada pelo tempo e espaço mágico. Há um hiperbolismo fabular do tempo e do espaço, os dias se reduzem em instantes, ao passo que os instantes se alongam. Os espaços são variados, mas ao mesmo tempo se completam e dão conta da temporalidade sonhada.

A partir da figura 16 até a figura 20, a aventura ganha um novo tom, pois o tempo da aventura deixa espaço para o tempo real, a extratemporalidade vai se desconstruindo para dar lugar apenas a real-temporalidade.

$\mathrm{Na}$ imagem 21, a real-temporalidade se instaura na narrativa, pois é o momento em que o tempo deixa de ser sonhado e passa a ser vivido/realidade. A presença forte do pai ou responsável, enquanto um sujeito de força e autoridade, exerce o seu papel disciplinador. O espaço, nesse novo tempo, deixa de ser o espaço abstrato, sonhado, fantasiado, e passa ser o espaço físico, real, o carrossel e caminho de volta para casa.

As categorias de tempo e espaço aqui identificadas conflui para uma coexistência simultânea, um antes e um depois que ganham forma em variados espaços da narrativa e se transformam em um só tempo e espaço, cujos sinais do tempo se revelam no espaço, e o espaço é medido pelo tempo. Daí a excepcional construção espaço-temporal da obra Bárbaro. Como afirma Bakhtin (2014, p. 362), "[...] o cronotopo é a porta de entrada para a compreensão dos significados", então cabe a nós leitores e educadores partimos da compreensão espaço-temporal da obra em busca dos seus possíveis significados.

Quando pensada essa relação e compreendidos os seus significados fica mais fácil pensar práticas de ensino significativas no âmbito educacional. Essa literatura infanto-juvenil aqui analisada é rica em detalhes significativos. Por se constituir um livro de imagens, ela transforma o leitor em autor da própria narrativa, abrindo espaço para o lúdico e o universo criativo do leitor. Entendidos esses pontos, resta ao educador construir a ponte entre a leitura e o leitor.

\section{CONSIDERAÇÕES FINAIS}

A leitura, nos contextos de ensino, deve ser um processo no qual o leitor realiza um trabalho ativo de compreensão e interpretação do texto, a partir dos objetivos, do conhecimento sobre o assunto, do que se sabe sobre o autor, de tudo o que se sabe sobre a linguagem. Não se trata de 
um trabalho de decodificação, mas de uma atividade que implica estratégias de leitura, sem as quais não seria possível uma leitura proficiente. Por isso, espera-se que nas aulas de Literatura o professor apresente propostas de textos cativantes para seus alunos, capazes de envolvê-los e de lhes proporcionar, acima de tudo, uma leitura prazerosa e crítica (BRASIL, 2006).

Mas para alcançar a criticidade é preciso compreender, interpretar, relacionar informações que ESTÃO inseridas no texto e que PODEM ser inseridas no texto. Neste estudo, apresentamos algumas reflexão sobre a leitura do texto literário com objetivo de contribuir para a formação desse leitor crítico e autônomo nas suas leituras. Apresentamos uma rápida interpretação da narrativa da obra "Bárbaro" (MORICONI, 2013) e refletimos sobre o tempo e o espaço que constitui a obra, considerando que há uma extratemporalidade e uma real-temporalidade incluídas na heterotemporalidade, em espaços variados que vão se construindo ao longo da narrativa, ora o espaço abstrato, sonhado, ora o espaço físico, real.

Para concluir, acreditamos que o aluno que lê desenvolve o senso crítico, melhora a escrita, a capacidade de argumentação e comunicação com o outro. Porém, os sentidos do texto, precisam ser construídos ao longo da interação entre leitor, autor e texto. E um dos fatores relevantes para que esses sentidos sejam alcançados é entender a constituição espaço-temporal da obra, pois toda a construção textual possui um tempo e um espaço de produção, que se mesclam e são responsáveis por uma gama de sentidos necessários para a compreensão do todo. Resta-nos então, em estudos futuros, refletirmos sobre possíveis práticas de ensino que considerem as reflexões espaçotemporais aqui apresentadas como meio de compreensão da narrativa e de formação de leitores cada vez mais críticos.

\section{REFERÊNCIAS}

BAKHTIN, M. M. Estética da Criação Verbal. Tradução do russo por Paulo Bezerra. $6^{a}$ ed. São Paulo: WMF Martins Fontes, 2011.

Formas de tempo e de cronotopo no romance. In: Questões de Estética e de Literatura. 5. ed. São Paulo: Annablume/Hucitec, 2014.

Teoria do romance II: as formas do tempo e do cronotopo. Tradução, posfácio e notas e Paulo Bezerra. Org. Serguei Botcharov e Vandim Kójinov. São Paulo: Editora 34, 2018.

BEMONG, N. et al. Bakhtin e o Cronotopo: reflexões, aplicações, perspectivas. São Paulo. Parábola. 2015.

BODGAN, Robert; BLIKEN, Sari. Investigação qualitativa em educação: uma introdução à teoria e aos métodos. Porto: Porto Editora, 1994.

BURKE, Peter. A fabricação do rei: a construção da imagem pública de Luís XIV. Rio de Janeiro: Jorge Zahar., 1994.

BRASIL. Secretaria de Educação Básica. Orientações Curriculares para o Ensino Médio. Linguagem, Códigos e suas Tecnologias. Brasília, 2006.

COSSON, Rildo. O espaço da literatura na sala de aula. In: PAIVA, Aparecida et al. (Coord.). Literatura: ensino fundamental. Brasília: Ministério da Educação, Secretaria de Educação Básica, 2010.

ECO, Umberto. Sobre algumas funções da literatura. In: . Sobre a literatura 2. ed. Rio de Janeiro: Record, 2003. 
GOMES, Saúl António. Vésperas Batalhinas. Estudos de História e de Arte. Leiria: Edições Magno, 1997.

MACHADO, I. A questão espaço-temporal em Bakhtin: cronotopia e exotopia. In: PAULA, L.; STAFUZZA, G. (Orgs.). Círculo de Bakhtin: teoria in(classificável). Campinas-SP: Mercado de Letras, 2010. (Série: Bakhtin: Inclassificável, v. 1).

MATOS, Eduardo Henrique da S. F. Espécies de plantas carnívoras e o seu cultivo Centro de Apoio ao Desenvolvimento Tecnológico - CDT/UnB, 2012. Disponível em < http://respostatecnica.org.br/dossie-tecnico/downloadsDT/OTA1Ng==> Acesso em: 05, nov. 2018.

MORSON, G. S; EMERSON, C. Mikhail Bakhtin: criação de uma prosaística. São Paulo: EDUSP, 2008.

MORICONI, Renato. Bárbaro. São Paulo: Companhia das Letrinhas, 2013.

VASCONCELLOS, Paulo Sérgio de. Mitos Gregos. São Paulo: Objetivo, 1998. Disponível em <http://www.filosofia.seed.pr.gov.br/arquivos/File/classicos_da_filosofia/mitos_gregos.pdf> Acesso em 05, nov. 2018. 